ISBN 978-981-14-1684-2

Proceedings of 2019 the 9th International Workshop on Computer Science and Engineering

(WCSE 2019 SUMMER)

Hong Kong, 15-17 June, 2019, pp. 352-357

doi: $10.18178 /$ wcse. 2019.06 .053

\title{
Design of Geological Disasters Warning System for Power- Transmission Lines
}

\author{
BinBin ZHAO ${ }^{1,+}$, WenHao OU ${ }^{1}$, Wei XIA ${ }^{2}$, Yi Liu ${ }^{1}$, WuYang ZHANG ${ }^{3}$, JianGuo MA ${ }^{4}$, \\ TunFang SONG ${ }^{5}$, JunJi CHEN ${ }^{3}$ \\ ${ }^{1}$ Power transformer engineering research institute, China Electric Power Research Institute Co., \\ Ltd., Beijing, China \\ ${ }^{2}$ Institute of Remote Sensing and Digital Earth, Chinese Academy of Sciences, Beijing, China \\ ${ }^{3}$ State Grid Chongqing electric power company, Chongqing, China \\ ${ }^{4}$ State Grid Hubei electric power Co., Ltd., Wuhan, China \\ ${ }^{5}$ State Grid Sichuan electric power company, Chengdou, China
}

\begin{abstract}
Due to the vast territory, complex geological conditions, and meteorological environments China has experienced frequent geological disasters. The various types, wide distribution, and significant destructiveness of geological disasters heavily impact the power-grid constructions. Moreover, in China, power transmission lines have wide cover-ranges and long distances along with various harsh geographical conditions. Especially with the influence of heavy rains, geological disasters (e.g., landslides and collapses) are easy to be introduced and seriously threatens the safety and stability. Thus, this study presents a multisource based geological disaster early warning system for the power-grid(MGDEWS-PG). Through collecting and analyzing the power-transmission lines, geological environment information, meteorological data and hidden hazard spots, the MGDEWS-PG achieves implementations of the map display, investigating historical disaster, monitoring, early warning and reporting the geological disasters. The realization of the MGDEWS-PG is able to improve the efficiency and efficiency of the geological hazard detection and control of transmission lines, improve the risk management and control ability of transmission lines, and provide a reliable scientific basis for disaster warning and emergency response.
\end{abstract}

Keywords : Geological disasters, ground disaster monitoring, ground disaster warning, multi-source data, system implementation

\section{Introduction.}

In recent years, geological disasters have occurred frequently in China. Due to the climate change, severe floods and frequent geological disasters poses great risks to the safety of power-transmission lines. It is current key word establish a geological disaster warning system for transmission lines for improving the ability of natural disaster resistance and actively responding to the threat of storms- and floods- introduced geological disasters. A power-grid geological disasters warning system should include the functions of displaying, inquiring, detecting, early warning and reporting ${ }^{[1]}$, which contribute to make timely protection measures to reduce the damages caused by disasters.

\section{MGDEWS-PG: A multi-source based geological disaster early warning system for the power-grid}

\subsection{Design and implement of the system}

\footnotetext{
Corresponding author. Tel.: + 18010131957; fax: +010-63463323

E-mail address: 123zhaobinbin@163.com
} 
As shown in Fig 1 The overall of the MGDEWS-PG includes three subsystems, namely the authority system, B/S system, and the early warning service ${ }^{[2]}$.

Among them, the authority system is mainly used to manage information and permissions for users and roles. The early warning service is mainly used to process the rainfall formation and predefined geological disaster data, and then acquire waring information of the landslides and mudslides in various regions of China for finally carrying out disaster warning. The B/S system mainly realize the calls of multi-source data. Compared with the C/S system, the B/S system has the advantages of distributions, strong sharing, simple development and maintenance, and low requirements on the client computer. The specific system composition structure is shown in Fig 2. In the B/S system, using layered deployment the multi-source data is organized and compressed from the data layer via the application service layer, and then transmitted through the Internet, finally displayed on the interface for users' calls.

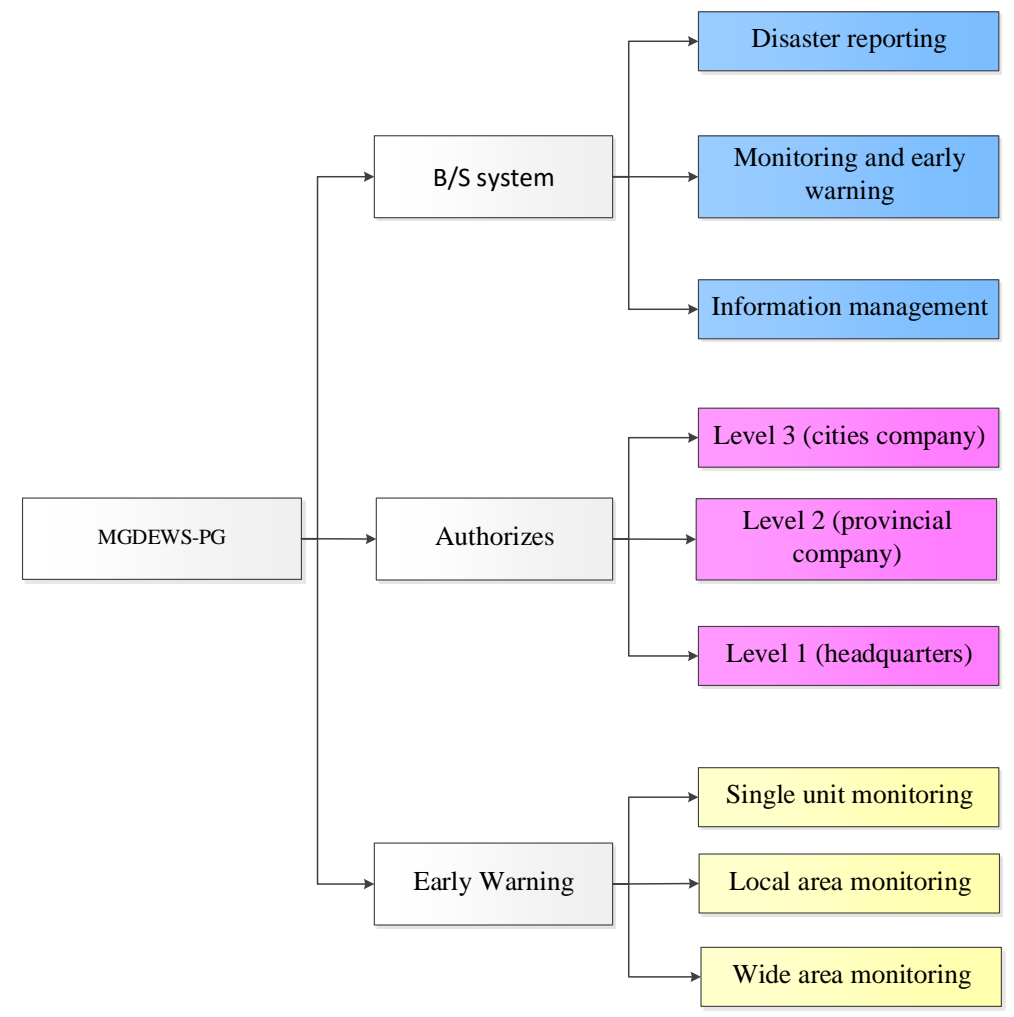

Fig 1: System architecture diagram

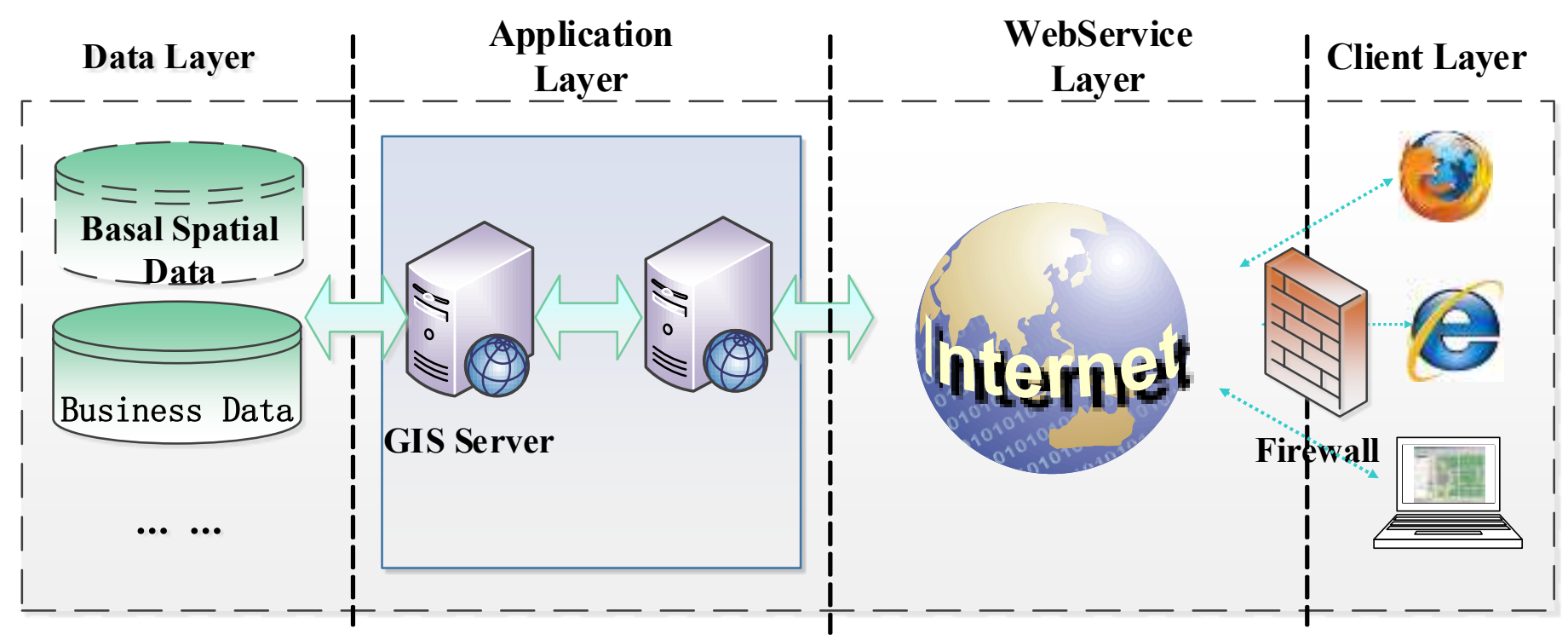

Fig 2: Diagram of the B/S system 


\section{Selection and Representation of Monitoring Data}

The multi-source data used in the system mainly are: power-transmission lines data, geological disaster environment information, meteorological data and hidden danger spots ${ }^{[3-5]}$. The detailed data is as follows:

\subsection{The power-transmission lines data}

Table 1: The attribute table of power tower spot

\begin{tabular}{|l|l|c|c|c|c|c|c|c|}
\hline Attribute & Type & Unit & Precision & Range & Required & Primary Key & Display & Instructions \\
\hline GUID & string & - & - & - & $\mathrm{N}$ & $\mathrm{Y}$ & $\mathrm{Y}$ & - \\
\hline Province & string & - & - & - & $\mathrm{N}$ & - & $\mathrm{Y}$ & - \\
\hline Voltage level & string & - & - & - & $\mathrm{N}$ & - & $\mathrm{Y}$ & - \\
\hline ID & string & - & - & - & $\mathrm{N}$ & - & $\mathrm{Y}$ & - \\
\hline Lon & string & - & - & - & $\mathrm{N}$ & - & $\mathrm{Y}$ & - \\
\hline Lat & string & - & - & - & $\mathrm{N}$ & - & $\mathrm{Y}$ & - \\
\hline Name & string & - & - & - & $\mathrm{N}$ & - & $\mathrm{Y}$ & - \\
\hline
\end{tabular}

Table 2 : The attribute table of a power-transmission line

\begin{tabular}{|l|l|l|l|l|l|l|l|l|}
\hline Attribute & Type & Unit & Precision & Range & Required & Primary Key & Display & Instructions \\
\hline GUID & String & - & - & - & N & Y & Y & - \\
\hline Province & String & - & - & - & N & - & Y & - \\
\hline Voltage level & string & - & - & - & N & - & Y & - \\
\hline ID & string & - & - & - & N & - & Y & - \\
\hline Name & string & - & - & - & N & - & Y & - \\
\hline
\end{tabular}

\subsection{Geological environment information}

Geological environment information includes raster data of topographical features, seismic intensity, slope, and geotechnical types across the country ${ }^{[6,7]}$.

\subsection{Meteorological data ${ }^{[8]}$}

Meteorological data mainly refers to precipitation including raster data of hourly rainfall across the country. In order to use the precipitation data for grid calculation, it is necessary to transform the existing hourly precipitation raw data into the future 24-hour precipitation raster data and 72-hour data.

\subsection{Hidden disaster spot}

To obtain the data of hidden danger spots, it is necessary to conduct a general survey of the country-wide power-transmission lines and conclude the statistical data. The specific attributes of hidden disaster spots are list in Table 3.

Table 3: The attributes table of hidden disaster spots

\begin{tabular}{|l|l|l|l|l|l|l|l|l|}
\hline \multirow{2}{*}{ Attribute } & Type & Unit & Precision & Range & Required & Primary Key & Display & Instructions \\
\hline GUID & String & - & - & - & $\mathrm{N}$ & $\mathrm{Y}$ & $\mathrm{Y}$ & - \\
\hline Name & string & - & - & - & $\mathrm{N}$ & - & $\mathrm{Y}$ & - \\
\hline Voltage level & string & - & - & - & $\mathrm{N}$ & - & $\mathrm{Y}$ & - \\
\hline lon & string & - & - & - & $\mathrm{N}$ & - & $\mathrm{Y}$ & - \\
\hline lat & string & - & - & - & $\mathrm{N}$ & - & $\mathrm{Y}$ & - \\
\hline
\end{tabular}




\begin{tabular}{|l|l|l|l|l|l|l|l|l|} 
Id & string & - & - & - & $\mathrm{N}$ & - & $\mathrm{Y}$ & - \\
\hline Danger Type & string & - & - & - & $\mathrm{N}$ & - & $\mathrm{Y}$ & - \\
\hline Primary Cause & string & - & - & - & $\mathrm{N}$ & - & $\mathrm{Y}$ & - \\
\hline Volume & string & - & - & - & $\mathrm{N}$ & - & $\mathrm{Y}$ & - \\
\hline Control or Not & string & - & - & - & $\mathrm{N}$ & - & $\mathrm{Y}$ & - \\
\hline Measurement & string & - & - & - & $\mathrm{N}$ & - & $\mathrm{Y}$ & - \\
\hline $\begin{array}{l}\text { Ever Occurred } \\
\text { Disaster }\end{array}$ & string & - & - & - & $\mathrm{N}$ & & $\mathrm{Y}$ & - \\
\hline Risk Level & string & - & - & - & $\mathrm{N}$ & - & & $\mathrm{Y}$ \\
\hline Remarks & string & - & - & - & $\mathrm{N}$ & - & $\mathrm{Y}$ & - \\
\hline
\end{tabular}

\section{Main functions of the MGDEWS-PG}

\subsection{Map display}

The map display part is mainly used to provide overlay and browsing of rainfall, hidden danger spots and geological disaster warning information on two-dimensional maps and three-dimensional spheres. Meanwhile, the distribution of rainfall, hidden danger spots, and stations can be clearly observed and directly seen by zooming in.

\subsection{Historical disasters}

The historical disasters part is used to display the spatial distribution of hidden danger spots and sites information. In this section, you can view the specific information of the sites. The information of hidden danger spots includes the line name, the tower number, the disaster type, the voltage level, the main incentives, and processing methods. The historical data query function can query and list the historical geological disasters data.

\subsection{Geological disasters detection}

The geological disasters detection part can manage data the power-transmission line of each voltage level, and can also manage the accumulated-deformation, deformation-rate data, and environment monitoring data.

\subsection{Geological disasters warning}

The early warning part is used to publish the meteorological risk waring map and reports of geological disasters in the next 24 hours and 72 hours. According to the waring results and power-transmission lines distributions, it can list the UHV line section which locate in the grade IV and V risk area so as to realize the early warning to the line sections the towers.

\subsection{Geological Disasters reporting}

In the geological disasters reporting part, through the establishment of the disaster reporting mechanism, the reporting and approval of the disaster information and the census information before the flood season can be achieved. At the same time, this part can realise the downloading of relevant documents for the geological disasters of power-transmission lines.

\subsection{Operation and maintenance center}

The operation and maintenance center is mainly used to manage user information and role information including query, add, edit, delete, and reset passwords. Also, users can view the login logs. 


\subsection{User center}

User center is mainly design for modification, viewing of personal information, and modification of personal login password.

\subsection{The early warning service}

The early warning service is mainly used to process specific rainfall information and process early warning data according to the predefined early warning models. The major functions include three modules: rainfall FTP file monitoring service, rainfall decompression service, and geological disaster warning service. The rainfall FTP file monitoring service is used to monitor the configured monitoring path. The detection file format is '.tar'. After the file is added, the file upload function is triggered and the log is recorded. After that, the rainfall files will be pushed to the configured FTP address. The rainfall decompression service is used to monitor the rainfall file to the specified folders. When the newly were added, they will be copied to the wording folder and decompressed. So that, a start request is sent to the early warning service. The geological disasters warning service is used to obtain 24 and 72 hours nationwide and provincial early warning data for landslides and debris flows based on specified rainfall information and preset landforms, slope, earthquake, and lithology preset data and a series of data processing according to predefined landslides and debris flows formulas.

\section{Conclusions}

This paper proposes a power-grid geological disaster early warning system based on multi-source data. The system adopts B/S subsystem composition method, which is used to analyze the power-lines information, geological disaster activity process and environment information to realize the display of geological disasters along power-lines, monitoring, early warning, and reporting of geological disasters. The implementation of this system will help to fully integrate the information and resources of power-transmission lines, promote the sharing of resources of various departments, and use information technology to monitor and warn the geological disasters and improve the informationization in the field of power=grid construction. Therefore, it is able to carry out targeted preplans, reduce accidents and costs of operations and management, and speed up the reaction speed when disasters occur.

\section{Acknowlegement}

This work was supported by a grant from National Key R\&D Program of China (2018YFC0809400), the science and technology project of State Grid (Research and application on intelligent monitoring and early warning technology of geological hazard for power transmission line based on InSAR, GCB17201700121) and Academy Innovation Fund of China Electric Power Institution (5242001700FA).

\section{References}

[1] GONG Qinghua, HUANG Guangqing, GUO Min, ZHANG Yueqiao. Present status of research and its developmental tendency on prediction and early warning of geologic hazards [J].Global Geology,2006(03):296302.

[2] YUE Jianwei, WANG Bin, LIU Guohua, CAI Hongchun, ZHOU Yucai, Yu Guangwen. Application study on early warning forecast and information management system of geological disaster [J].Journal of Natural Disasters, 2008,17(06):60-63.

[3] WU Shuren, SHI Jusong, ZHANG Chunshan, WANG Tao. Preliminary discussion on technical guideline for geohazard risk assessment [J].Geological Bulletin of China,2009,28(08):995-1005.

[4] SU Baiyan, XU Qiang, HUANG Jian, LIANG Fan. Design and implementation of monitoring and warning system for geological disaster based on dynamic data-driven technology [J].Journal of Chengdu University of Technology(Science \& Technology Edition),2018,45(05):615-625.

[5] YANG Xuelian, WU Kai, LI jia. Research and application of multi-information publishing platform for geological disaster monitoring[J]. Hunan Communication Science And Technology,2018,44(01):43-45+53.

[6] ZHAO Junsan, KE Zunjie , CHEN Guoping, YUAN Lei, GU miao, WANG Tao. Implementation of the 
Geological Hazard Monitoring and Early Warning System Based on Multi-source Spatial Data--a Case Study of Deqing County, Yunnan Province[J].GEOMATICS WORLD,2017,24(03):35-41.

[7] Liu shuxia. The Study of Geological-body Numerical Simulation based on Geo-hazard Monitoring and early Warning Platform [D].Chengdu University of Technology,2013.

[8] LIU Yanhui, LIU Chuanzheng, WEN Mingsheng, TANG Can. Study of Early Warning Models for Regional Geohazards in China [J]. Journal of Engineering Geology,2015,23(04):738-746. 